\title{
The rapid adaptation of SARS-CoV-2-rise of the variants: transmission and resistance
}

\author{
Sandrine M. Soh ${ }^{1}$, Yeongjun Kim ${ }^{1}$, \\ Chanwoo Kim ${ }^{1}$, Ui Soon Jang ${ }^{1}$, \\ and Hye-Ra Lee ${ }^{1,2 \star}$ \\ ${ }^{1}$ Department of Biotechnology and Bioinformatics, College of Science and \\ Technology, Korea University, Sejong 30019, Republic of Korea \\ ${ }^{2}$ Department of Lab Medicine, College of Medicine, Korea University, \\ Seoul 02841, Republic of Korea \\ (Received Jun 30, 2021 / Revised Aug 9, 2021 / Accepted Aug 9, 2021)
}

The causative factor of COVID-19, severe acute respiratory syndrome coronavirus 2 (SARS-CoV-2) is continuously mutating. Interestingly, identified mutations mainly occur in the spike (S) protein which interacts with the ACE2 receptor and is cleaved via serine protease TMPRSS2. Some mutated strains are becoming dominant in various parts of the globe because of increased transmissibility as well as cell entry efficacy. Remarkably, the neutralizing activity of monoclonal antibodies, convalescent sera, and vaccines against the variants has been reported to be significantly reduced. Therefore, the efficacy of various monoclonal antibodies therapy and vaccines against these variants is becoming a great global concern. We herein summarize the current status of SARS-CoV2 with gears shifted towards the recent and most common genetic variants in relation to transmission, neutralizing activity, and vaccine efficacy.

Keywords: SARS-CoV-2, transmission, vaccine, neutralization, monoclonal antibodies, variants

\section{Introduction}

The severe acute respiratory syndrome coronavirus 2 (SARSCoV-2) is the causative agent of the COVID-19 pandemic, that poses an overwhelming threat on global health systems alongside a notable mortality (Han et al., 2020). COVID-19 generally manifests via symptoms such as fever, cough, chest discomfort, fatigue, anosmia, abdominal pain and in severe cases dyspnea, and bilateral lung infiltration (Gralinski and Menachery, 2020; Young et al., 2020). SARS-CoV-2 which belongs to the beta-coronavirus genus, is a single-stranded, po-

${ }^{\star}$ For correspondence. Email: leehr@korea.ac.kr; Tel.: +82-44-860-1831 Copyright (C) 2021, The Microbiological Society of Korea sitive-sense RNA virus harboring four main structural proteins; Spike (S), envelope (E), membrane (M), and nucleocapsid $(\mathrm{N})$ as well as several non-structural proteins (Chan et al., 2020). The genetic proofreading mechanism present in SARS-CoV-2 but not in other RNA viruses, has not preserved it from genomic mutation. This genomic mutation could be due to natural evolution and/or immune selection pressure (Song et al., 2005; Sevajol et al., 2014; Koyama et al., 2020; Ou et al., 2021). Hence, numerous SARS-CoV-2 variants have emerged and have been classified by various nomenclature systems including WHO, Nextstrain, Pango, and GISAID (Table 1). For example, according to the latter nomenclature system, SARS-CoV-2 variants are classified within eight major clades (L, S, V, G, GH, GR, GV, and GRY) based on the mutation sites of their genome. Among them, the $\mathrm{G}$ clade harboring the $\mathrm{D} 614 \mathrm{G}$ mutation of S protein, which is recognized as the largest clade has three subclades namely $\mathrm{GH}, \mathrm{GV}$, and GR evolving into GRY associated with it (Mercatelli and Giorgi, 2020; Hamed et al., 2021; Sengupta et al., 2021). The G clade especially has been reported with significantly higher infectivity and transmissibility due to various mutations in the S protein (Ozono et al., 2021).

The $S$ protein is incorporated into the viral envelope and facilitates viral entry into the host cells. The $S$ protein binds to the angiotensin converting enzyme 2 (ACE2) and is activated via proteolytic cleavage by host proteases TMPRSS2 near the junction around its S1 and S2 domains (Shang et al., 2020). Indeed, the $S$ protein consists of two functional subunits S1 and S2, which are responsible for cellular receptor binding and fusion of viral envelope with cellular membrane respectively (Shang et al., 2020; Walls et al., 2020; Ali et al., 2021). Since the S protein is critical for viral entry, mutations in the S protein have a powerful influence on the infectivity, transmissibility, and pathogenesis. Since the current vaccines target the ancestor strain of SARS-CoV-2, the effect of these vaccines on the new variants is now questionable. Owing to end the COVID19 pandemic, the development of novel strategies is urgently needed. We therefore in this brief review summarize current knowledge of SARS-CoV-2 with respect to dominant genetic variations in relation to transmission, neutralization, and vaccine strategies.

\section{Life Cycle}

The SARS-CoV-2 consists of ten or more open reading frames (ORFs) encoding 29 proteins (Li et al., 2020). Among them 
Table 1. The notable variants of SARS-CoV-2 and clinical differences

\begin{tabular}{|c|c|c|c|c|c|c|}
\hline Pango lineages & $\begin{array}{l}\text { Nextstrain } \\
\text { clade }\end{array}$ & $\begin{array}{l}\text { GISAID } \\
\text { clade }\end{array}$ & WHO label & $\begin{array}{l}\text { Potential origin (first } \\
\text { documented sample) }\end{array}$ & Notable S mutation & Effect of variant clinically \\
\hline B.1.1.7 & 20I (V1) & GRY & Alpha $(\alpha)$ & UK & 69/70 del, N501Y, P681H & $\begin{array}{l}\text { Higher transmissibility }(\sim 70 \%) \text { and lethality } \\
(\sim 60 \%) \text {. Moderate decrease of neutralization } \\
\text { efficiency }\end{array}$ \\
\hline B.1.351 & $20 \mathrm{H}(\mathrm{V} 2)$ & GH/501Y.V2 & Beta $(\beta)$ & South Africa & K417N, E484K, N501Y & $\begin{array}{l}\text { Higher transmissibility (20-113\%), significant } \\
\mathrm{mAb} \text { neutralization efficiency reduction }\end{array}$ \\
\hline B.1.617.1 & $21 \mathrm{~B}$ & G/452R.V3 & Kappa (к) & \multirow{2}{*}{ India } & \multirow{2}{*}{ L452R, E484Q, P681R } & \multirow{2}{*}{ Reduction in neutralization efficiency } \\
\hline B.1.617.2 & $20 \mathrm{~J}(\mathrm{~V} 3)$ & GR/501Y.V3 & Delta $(\delta)$ & & & \\
\hline B.1.1.284 (P.1) & $21 \mathrm{~A}$ & G/478K.V1 & $\operatorname{Gamma}(\gamma)$ & Brazil & K417T, E484K, N501Y & $\begin{array}{l}\text { Higher transmissibility }(\sim 161 \%) \text { and increased } \\
\text { lethality }(\sim 80 \%) \text { and reduction in } \\
\text { neutralization efficiency }\end{array}$ \\
\hline $\begin{array}{l}\text { B.1.427 } \\
\text { B.1.429 }\end{array}$ & $21 \mathrm{C}$ & GH/452R.V1 & Epsilon $(\varepsilon)$ & USA & S13I, W152C, L452R & $\begin{array}{l}\text { Higher transmissibility }(\sim 20 \%) \text { and moderate } \\
\text { reduction in neutralization efficiency }\end{array}$ \\
\hline
\end{tabular}

as mentioned earlier is the $\mathrm{S}$ protein, a homotrimeric glycoprotein that consists of two distinct subunits (S1 and S2) (Sternberg and Naujokat, 2020). The S1 subunit contains the receptor-binding domain (RBD) which is exposed transiently via conformational change after cleavage between $\mathrm{S} 1$ and S2, leading to interaction with ACE2 receptor (Juraszek et al., 2021). Notably, the polybasic furin cleavage site at S1/S2 junction of the SARS-CoV-2 was demonstrated to allow for this conformational arrangement of the S protein, enabling it to bind the ACE2 receptor with higher affinity compared to SARS-CoV-2 S protein (Coutard et al., 2020). The S2 subunit likely occurs membrane fusion process between the viral and host membrane. Hence, initial S protein priming depends on TMPRSS2 and is critical for entry of SARS-CoV-2. In line with this point of view, Bestle et al. (2020) demonstrated that inhibition of either TMPRSS2 or furin activity via MI-432 or MI-1851 inhibitors respectively, strongly suppresses replication efficacy of SARS-CoV-2. These results suggest both proteases have crucial roles in life cycle of SARSCoV-2 and are possible targets for these compounds against COVID-19 (Bestle et al., 2020). In the other hand, apart from receptor mediated endocytosis, SARS-CoV-2 uses clathrinmediated endocytosis. After endocytosis, the $\mathrm{S}$ protein is activated by action of furin and cathepsin $\mathrm{B} / \mathrm{L}(\mathrm{CatB} / \mathrm{L})$ proteases, thus allowing for viral-endosomal membrane fusion and later viral RNA release into the cytoplasm (Bestle et al., 2020). Studies have demonstrated that inhibitors of clathrinmediated endocytosis reduce viral internalization and as such would be potential therapeutic target. For instance, in a study conducted by Bayati et al. (2021) endocytosis of SARS-CoV-2 $S$ protein was reduced when HEK-293T cells stably expressing ACE2 were exposed to two inhibitors; Dynasore and Pitstop2. Dynasore blocks the GTPase dynamin that drives the fission of clathrin-coated pits from the plasma membrane while Pitstop 2 prevents clathrin heavy chain from interacting with adaptor proteins required for clathrin-coated pit formation (Macia et al., 2006; von Kleist et al., 2011). Taken together, the importance of host proteases which are involved in entry steps of SARS-CoV-2 have gotten attention as potential therapeutic targets to cure COVID-19 (Coutard et al., 2020).

Once SARS-CoV-2 releases its genome into the cytoplasm, the replicative cycle starts with translation of ORF1a and ORF1ab from the genomic RNA. These ORFs produce two polyproteins, ppla and pplab, which by the action of viral proteases are split into 16 nonstructural proteins (NSPs). These NSPs, mainly NSP3 and NSP4 induce the formation of double membrane vesicles (DMVs) which appear to play a role as replication-transcription complexes (RTCs), carrying out synthesis of genomic viral RNA (Wang et al., 2020; Wong et al., 2021). NSPs also encompass critical roles for viral genome replication. For instances, NSP12 acts as an RNA dependent RNA polymerase (RdRp), NSP8-NSP7 as processivity clamp for RNA polymerase, NSP13 as a helicase, and NSP9 as a single-strand RNA-binding protein (Ivanov et al., 2004; Kirchdoerfer and Ward, 2019). The mRNAs of structural proteins the $\mathrm{S}, \mathrm{E}$, and $\mathrm{M}$ undergo translation via the ribosomes on the endoplasmic reticulum (ER) to produce the corresponding proteins, which are subsequently transported to the Golgi apparatus for virion assembly. The mature virus particles are produced in the endoplasmic reticulum-Golgi intermediate compartment (ERGIC) by the association with nucleocapsid (Masters, 2006; Fehr and Perlman, 2015; Astuti and Ysrafil, 2020). The viral nucleocapsid (also called the vRNP which is composed of RNA together with $\mathrm{N}$ protein) is synthesized in the cytoplasm and transported to the ERGIC for virus particle production (Fehr and Perlman, 2015). The $\mathrm{N}$ protein then catalyzes the formation of premature virus particles with $\mathrm{E}$ and $\mathrm{M}$ proteins forming the envelope that will enclose the vRNP leading to viral envelopment. Finally, the $\mathrm{S}$ proteins are incorporated into the virion and these progeny viruses are then transported to the cell membrane in vesicles for release by exocytosis (Poduri et al., 2020).

\section{Pathogenesis and Transmission}

SARS-CoV-2 infection primarily targeting the lungs leads to ACE2 downregulation and deficiency, subsequently causing an imbalance in the renin angiotensin system (RAS) (Vaduganathan et al., 2020). ACE2 regulates the RAS and a disruption in its functioning can lead to inflammation as observed in SARS-CoV-2 patients (Tay et al., 2020). The destabilization in the RAS occurs high angiotensin II plasma level and TNF- $\alpha$ overproduction, which contribute to inflammation. All these events characterize the pulmonary clinical phase of the disease (Glowacka et al., 2010). This pul- 
monary phase is followed by the proinflammatory phase in which the immune system recognizes the viral antigens. These antigens are processed and presented to both natural killer (NK) cells and CD8-positive cytotoxic T-cells. This leads to the activation of both the innate and adaptive immunity, thereby triggering the production of large amounts of proinflammatory cytokines and chemokines (Coperchini et al., 2020; Picchianti Diamanti et al., 2020; Ragab et al., 2020; Gao et al., 2021). Lymphopenia that results from SARS-CoV2 infection can further exacerbate this cytokine production in the course of immune compensation (Fathi and Rezaei, 2020; Market et al., 2020). This massive cytokine production and release into blood results in a cytokine storm, causing the prothrombic phase its thrombotic tendency, multi-organ failure, and eventually death (Li et al., 2020; Lippi et al., 2020). Many studies portray the elder age group usually above 55 years to be more vulnerable to infection, thus at a higher risk of developing severe illness than the younger age group (Chakravarty et al., 2020; Nikolich-Zugich et al., 2020). For instance, when the young and middle-aged patients were compared to patients older than 65 years, the latter presented more severe symptoms such as elevated inflammation indices and lymphocytopenia (Yang et al., 2020). Another study during its investigating of 17 acute and 24 convalescent patients found that, patients older than 55 years had reduced production capacities of cytokines like IFN- $\gamma$ and IL- 2 by CD4+ and CD8+ T-cells. In addition, their T-cell activation by dendritic cells was impaired (Zhou et al., 2020). These results tend to agree with the high morbidity and mortality observed in the elderly.
The fact that immunological response to infection reduces with ageing, suggests that elderly age group may be more prone to infection by SARS-CoV-2 compared to the younger age groups.

The cellular tropism of SARS-CoV-2 and its detection in various tissues and organs can be accounted for by the expression of ACE2 receptors on a wide range of cells given its importance in normal cell physiology (Gao and Zhang, 2020; Gheblawi et al., 2020; Hui et al., 2020). The huge number of infected individuals and the high viral load produced during each infection offer opportunities for SARS-CoV-2 mutations to arise through immune selection especially with increasing population immunity. As a result of immune selection pressure, viral adaptation via mutation majorly in the $S$ protein has allowed for major variants to show notable transmission improvements (Luan et al., 2021). Along with the predominant variant D614G mentioned earlier, the variants of concerns (VOC) B.1.1.7, B.1.351, and B.1.1.248 (also known as P.1) have been reported to spread faster and are gaining ground across the globe (Abdool Karim and de Oliveira, 2021; La Rosa et al., 2021). All three of these variants have a common mutation (N501Y) in the RBD of the S protein. This mutation is responsible for the increase transmissibility of the mutants compared to that of the Wuhan strain (Boehm et al., 2021; Luan et al., 2021). Apart from the common mutation N501Y, the B.1.351, and B.1.1.248 variants have two additional mutations (E484K with $\mathrm{K} 417 \mathrm{~N}$ and $\mathrm{E} 484 \mathrm{~K}$ with K417T, respectively) in their S protein (Wibmer et al., 2021; Zhou et al., 2021). The pseudotyped virus bearing the

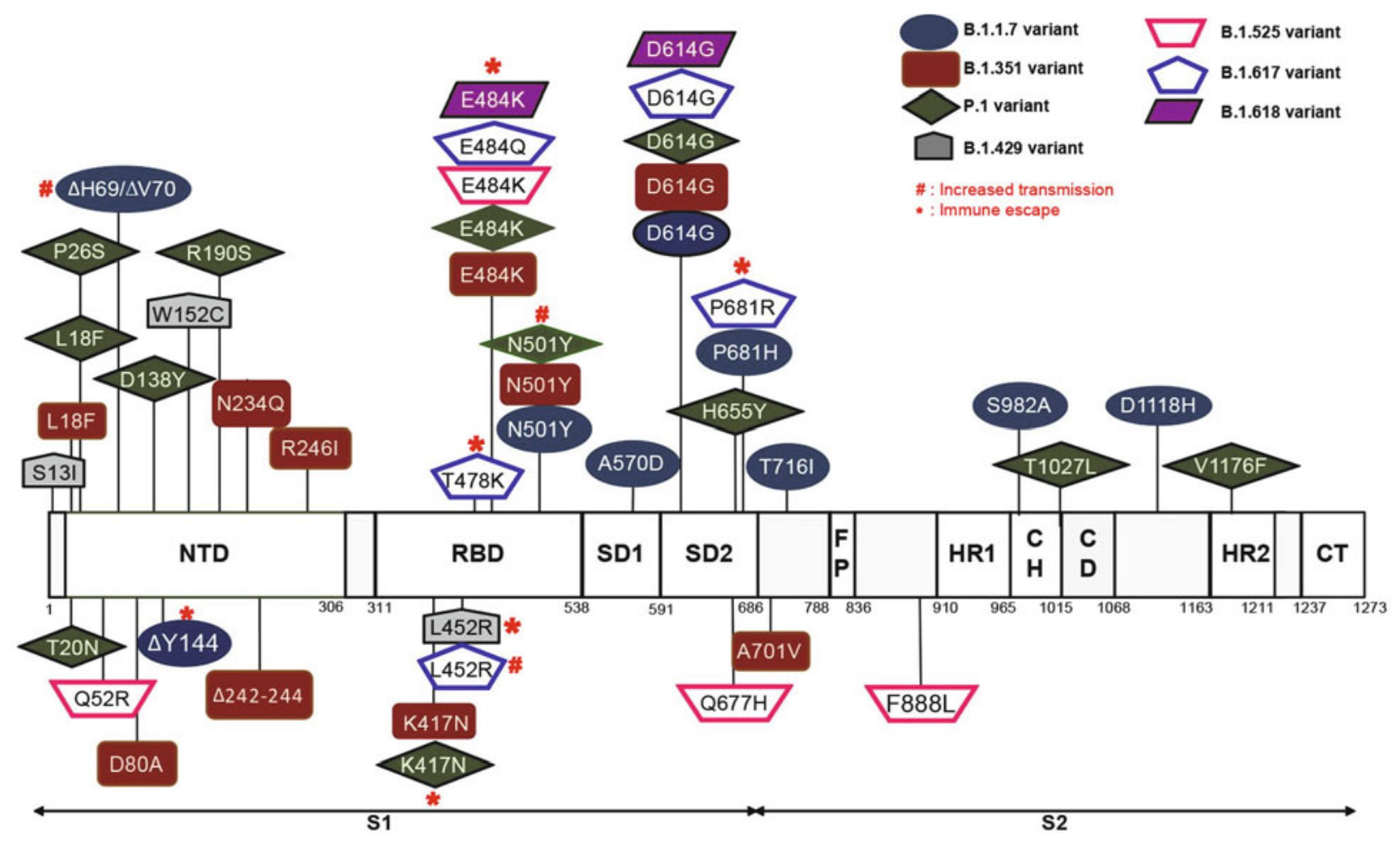

Fig. 1. Spike protein domain showing various variant mutations. This figure illustrates the $S$ mutations of the major variants designated by various shapes as described by the legend. The mutations of which influence transmission or infectivity are represented by sharp or star signs; N-terminal domain (NTD), receptor-binding domain (RBD), subdomain 1 and 2 (SD1\&2), fusion peptide (FP), heptad repeat 1 and 2 (HR1\&2), central helix (CH), connector domain $(\mathrm{CD})$, and cytoplasmic tail (CT). 
B.1.351 S mutations was shown to have a higher transmissibility and infectivity compared to N501Y bearing pseudotyped virus. This could be explained by the drastically enhanced cell-cell fusion observed in Vero cells infected with the pseudotyped virus bearing the B.1.351 mutations (Kim et al., 2021). In addition, the E484K mutation found in the B.1.351 variant has equally been reported to increase binding affinity between the S protein and its receptor ACE2. In effect, the E484K mutation was reported to result in favorable electrostatic interactions, compensating the burial of the charged and polar groups upon binding of RBD with hACE2. This compensation in turn significantly improves the RBD-hACE2 binding affinity (Wang et al., 2021b). While the E484K mutation enhances binding of the $\mathrm{S}$ protein to its receptor, it reduces binding of neutralization antibodies. Reduced binding affinity of the neutralization antibodies allows for immune escape which contributes to increased transmissibility of variants bearing this mutation (Collier et al., 2021; Faria et al., 2021; Zhou et al., 2021). The recently reported California variants B.1.427 and B.1.429 bearing the S mutations S13I, W152C, and L452R were demonstrated to have 18.6-24\% increase in transmissibility relative to wild type (WT) strain. A 2-fold increase in infectivity was observed when 293T cell cultures and lung organoids stably expressing ACE2 were infected with L452R pseudotyped virus compared to WT. In addition, viral shedding was increased by 2 -fold in vivo (Deng et al., 2021). In effect, the L452R mutation has been demonstrated to directly connect to the ACE2 receptor (Chen et al., 2020). However, in the case of the L452R S mutation, its location in the hydrophobic patch of the S-RBD may cause some conformational changes of the $\mathrm{S}$ protein thereby stabilizing its interaction with the receptor, which in turn may lead to increased infectivity (Motozono et al., 2021). The recently trending variants B.1.617 and B.1.618 have shown rapid spread in some parts of the globe. The B.1.617 variant designated as a VOC possesses the mutations L452R, E484Q, and P681R in the S protein while the B.1.618 assigned as variant of interest possesses the mutations $\Delta 145$ 146, E484K, and D614G in S protein (Tada et al., 2021). The E484Q mutation in the S RBD of B.1.617 variant is the target of neutralizing antibodies similar to the E484K mutation in the B.1.351, B.1.1.248, and B.1.618 variants. The B.1.617L452R mutation identifies with the L452R mutation in the B.1.427 and B.1.429 variants (Deng et al., 2021; Singh et al., 2021). The P681R mutation in the B.1.617 lineage is found in the polybasic cleavage site region of its $S$ protein and may enhance processing by host proteases which results in a greater viral load and potential increased transmission. The P681R mutation has been reported to increase syncytia formation and as such may account for the increased pathogenesis that was observed in a prior study using hamster model (Mlcochova et al., 2021; Yadav et al., 2021). However, no basic evidence of this increased pathogenicity has yet been found in the human setting. The arising of all these variants with various mutations in their S protein (Fig. 1) without out-looking the future ones, calls for more surveillance and particularly more consideration for the elaboration of vaccines given their major target is the $\mathrm{S}$ protein of the WT strain.

\section{Monoclonal Antibodies Therapy}

Monoclonal antibodies (mAbs) are copies of an antibody that targets one specific antigen. Monoclonal antibodies are mostly used for therapy as they enter the bloodstream immediately after injection and provide rapid protection thus, can be applied to all individuals. Patients infected with COVID-19 have been shown to generate antibodies that can neutralize the infection (Jiang et al., 2020; Garcia-Beltran et al., 2021). The neutralizing activity of COVID-19 patients' plasma was correlated with the magnitude of antibody responses to SARSCoV-2 S and N proteins (Post et al., 2020). To this effect, $\mathrm{mAbs}$ have been developed majorly against the $\mathrm{S}$ protein of SARS-CoV-2 owing to prevent SARS-CoV-2 infection and limit advancement to severe disease in patients with mild to moderate conditions (Lloyd et al., 2021). Disease progression is limited particularly in those who have not yet developed an endogenous antibody response (Weinreich et al., 2021). Towards this goal, most commercial mAbs have been developed against S protein especially its immunodominant epitopes including RBD, RBM (receptor binding motif), and NTD (N-terminal domain) (Hansen et al., 2020; McCallum et al., 2021b; Min and Sun, 2021). One of the FDA authorized $\mathrm{mAb}$ is Bamlanivimab (also known as LY-CoV555) sponsored by AbCellera/Eli Lilly Company. Bamlanivimab binds to the $S$ protein $\mathrm{RBD}$, blocking it from binding to ACE2 receptor thereby preventing viral attachment to host cell (DeFrancesco, 2021). The efficacy of Bamlanivimab was shown by a phase 2 trial involving 465 outpatients diagnosed with mild or moderate COVID-19. The patients received a single intravenous infusion of Bamlanivimab as monotherapy, resulting to $99.97 \%$ elimination of viral RNA load 11 days postadministration (Mahase, 2020; Liu et al., 2021c). Bamlanivimab also showed an efficient neutralization of the SARSCoV-2 variant B.1.1.7 (Widera et al., 2021). In a panel of $S$ protein $\mathrm{RBD} \mathrm{mAbs}$ against B.1.1.7, the neutralizing activity was complete for some mAbs (DH1041, DH1043, DH1047, and P2B-2F6) and partially inhibited for other mAbs (COVA118, COVA2-15, S309, and to a lesser extent, B38). The authors after modeling the N501Y mutation with $\mathrm{mAb}$ B38, observed a hindrance between the Y501 residue in S protein and S30 residue in $\mathrm{B} 38 \mathrm{mAb}$. The observed hindrance between both residues suggests the resistance to the $\mathrm{mAb}$ is due to the mutation at the N501 of S protein (Shen et al., 2021). Therefore, the B.1.1.7 variant may show some reduced neutralization however its immune escape potential is still benign.

Contrarily to B.1.1.7, the B.1.351 variant was reported to be resistant to most antibodies due to the E484K mutation in RBD of its S protein (Greaney et al., 2021; Wang et al., 2021c). Notably, the E484K mutation is demonstrated by mounting data to be responsible for the immune escape of all variants that bear it (Huang et al., 2021; Wang et al., 2021c). In a study, the binding affinity of a double mutated S protein ( $484 \mathrm{~K}$ / $501 Y-R B D)$ compared to WT S protein was increased. The double mutated $S$ protein was generated by introducing the E484K mutation in the S gene bearing only N501Y-RBD mutation. Interestingly, binding of this double mutated $S$ protein to Bamlanivimab in vitro was completely abolished implying resistance to neutralization (Liu et al., 2021c). Structural modeling suggests the resistance is due to loss of the three salt 
bridges that form between E484 and Bamlanivimab upon E484K mutation (Liu et al., 2021c). Concomitantly, another study reported the resistance of B.1.351 variant to most potent tested NTD mAbs and RBM mAbs including Bamlanivimab (Wang et al., 2021c). The resistance observed against the NTD mAbs was accounted for by the deletions of amino acid residues 242-244 and/or the R246I mutation all found in the NTD of the S protein. A recent study wherein the B.1.1.248 variant strain was exposed to RBD mAbs, then incubated with Vero cells, reported its markedly refractory character to Bamlanivimab (LY-CoV555), Etesevimab (CB6), potent RBM-mAbs 2-15, and C121 antibodies (Wang et al., 2021a). This refractory character would likely be as a result of the E484K mutation responsible for immune escape.

REGN-COV2 cocktail (consisting of Casirivimab [REGN10933] and Imdevimab [REGN10987] in equal doses) was reported to enhance viral clearance especially in patients with high viral load baseline. In this study, 269 outpatients were either given a placebo or REGN-COV2 in three groups with low doses group, high doses group, or combined group. The high dose group benefited the most with least-squares mean of $-0.56 \log 10$ copies per $\mathrm{ml} 7$ days post-vaccination. In addition, the mean reduction viral load was two-fold greater among patients with $\mathrm{mAb}$ than patients with placebo (Weinreich et al., 2021). Pseudotyped viruses bearing mutations of B.1.1.7 and B.1.351 variants, demonstrated resistance to Casirivimab antibodies but were completely neutralized by the REGN-COV2 cocktail (Weinreich et al., 2021). Wang et al. (2021a) evaluated the sensitivity of B.1.351 variant to Casirivimab and Imdevimab along with ACE2-Ig antibodies (developed in their previous study). This variant demonstrated resistance to all Regeneron antibodies but was sensitive to ACE2-Ig antibodies, suggesting a potential therapeutic candidate against SARS-CoV-2 and its variants (Wang et al., 2021a). Structural analysis data revealed that the E484K mutation in B.1.351 variant is located on the binding sites of the Regeneron mAbs. This prevents the mAbs from binding thereby explaining the observed resistance (Wang et al., 2021a). In effect, the E484 residue would normally form hydrogen bonds with monoclonal antibodies that target the RBM. Upon mutation, E484K causes steric clashes and charge change at antibody-binding sites, thus abolishing binding by the RBMmAbs. Interestingly, B.1.351 lineage pseudotyped viruses were partially neutralized by Casirivimab but effectively by Imdevimab using pseudotyped virus-based neutralization assay (Kim et al., 2021). This result supports the possible neutralization of B.1.351 variant by some mAbs originally directed against SARS-CoV-2 S protein. Therefore, the current $\mathrm{mAb}$ directed against the $\mathrm{S}$ protein (WT) can be effective against the emerging variants. In a recently published study, the B.1.1.248 variant and its pseudotyped viruses markedly abolished the neutralizing activity of Casirivimab but showed sensitive to Imdevimab (Wang et al., 2021a). Similar to the B.1.351 variant, the neutralizing activity of Casirivimab was inhibited when inoculated together with pseudotyped viruses bearing the B.1.1.248 mutations into Vero cells. This inhibition can be attributed to its E484K mutation, responsible for immune escape against antibodies (Hoffmann et al., 2021a). Hence, the E484k mutation clearly stands out as a warranted mutation highlighted by the resistance demon- strated to Casirivimab by both B.1.351 and B.1.1.248 variants which bear the E484k mutation.

Recently, from a panel of 377 neutralization monoclonal antibodies (NmAbs) generated from SARS-CoV-2-recovered individuals, 20 most potent NmAbs binding to nineteen RBD and one NTD were exposed to pseudotyped lentivirus bearing the B.1.617.1 variant mutations and to a live viral isolate of B.1.617.2. Compared to WT-Victoria isolate, both B.1.617.1 pseudotyped virus and live isolate B.1.617.2 showed a 5-fold reduction in neutralization titers measured using $\mathrm{FRNT}_{50}$ (focus reduction neutralization test 50). Interestingly, B.1.617.2 completely inhibited the neutralizing activity of NTD NmAb (mAb 159) but showed increased sensitivity to mAb 253, hence warning for further investigations (Liu et al., 2021a). When pseudotyped viruses bearing B.1.617 S protein, were exposed to Casirivimab and Imdevimab, $\mathrm{IC}_{50}$ of neutralization titers were reduced by 20 -fold and 3-fold respectively (Tada et al., 2021). A similar result was observed with pseudotyped virus bearing the E484K mutation upon exposure to Casirivimab. This result further confirms the immune-escape function of the E484K mutation, thus suggesting less protection against the B.1.617 variant. Concomitantly, another study showed that the inhibition of B.1.617 S protein-mediated entry into host was diminished by Casirivimab and Etsevimab but was total by Imdevimab. However, Bamlanivimab failed to inhibit its entry completely (Hoffmann et al., 2021b). Another study conducted by Planas et al. (2021) reported the resistance of B.1.617.2 to neutralization by NTD and RBD mAbs including Bamlanivimab, possibly as a consequence of its mutations. Conversely to B.1.617 variant, the B.1.618 variant in this study, did not affect the neutralization titers when exposed to the same mAbs (Tada et al., 2021). When pseudotyped viruses bearing the B.1.617 S mutations were exposed to cocktails of Casirivimab plus Imdevimab and Bamlanivimab plus Etesevimab, their host cell entry driven by the $S$ protein was less efficiently inhibited by the latter cocktail and completely inhibited by the former (Hoffmann et al., 2021b). Overall, the various studies point out the reduced activity of neutralization against the variants indicating their resistance and therefore warns for serious intervention in the development of broader protective neutralization antibodies.

A combined therapy of Etesevimab and Bamlanivimab was administered to 577 patients in a randomized phase $2 / 3$ study and a significant reduction in viral load was reported compared to the placebo group (Gottlieb et al., 2021). The efficacy of the monoclonal cocktail therapy REGN-COV2, which bind to the non-overlapping epitopes of $\mathrm{S}$ protein $\mathrm{RBD}$, was tested and reported to be effective on COVID-19 patients with mild to moderate symptoms. Indeed, significant virus reductions were observed within 28 days of administration (US FDA, 2020). This result was corroborated by another study of phase $1 / 2$ trials with 275 patients in which improved antibody efficacy was demonstrated in patients with high viral load and uninitiated endogenous immune responses (Weinreich et al., 2021). The observed output from the use of cocktail therapy or antibodies in combination uplifts and encourages while endowing us with a present way of slowing down the pandemic. However, we still observe a reduction in neutralization efficacy of the antibodies against the emerging variants. This cautions against the all-inclusive use of monoclonal anti- 
bodies and urges a need to re-consider the spectrum of action of various neutralizing antibodies that are being developed. Apart from neutralizing antibodies, mounting studies report the reduced neutralizing activity of convalescent sera (which contain endogenous antibodies) against the variants (Collier et al., 2021; Shen et al., 2021; Supasa et al., 2021). For instance, Shen et al. (2021) tested sera from 1-8 weeks post resolution of COVID-19 against B.1.1.7 variant and observed a 1.5 -fold decrease in $\mathrm{ID}_{50}$ and $\mathrm{ID}_{80}$ neutralizing titers. Similarly, another study reported modest reduction in neutralizing titers of convalescent plasma from SARS-CoV-2 WT-infected patients (Collier et al., 2021). Contrarily to this study, Cele et al. (2021) reported the effective neutralization of the B.1.351 variant using convalescent serum from a patient infected with B.1.351 variant. A month post symptom onset, plasma was collected from 14 patients infected with non-B.1.351variants from the first South African infection wave (Cele et al., 2021; Wibmer et al., 2021). Sequencing result of one of the 14 samples revealed the presence of E484K mutation. The observed effective neutralization of B.1.351elicuted serum suggest the possible use of variant sequencebased vaccines albeit the one sample result. Pseudotyped viruses with B.1.617 and B.1.618 S protein when exposed to convalescent sera from patients infected with WT SARS-CoV2 , showed a 2.3 -fold and 2.8 -fold resistance to neutralization compared to viruses with $\mathrm{S}$ (WT) protein respectively (Tada et al., 2021). Recently, a study reported protection from B.1.1.7-convalescent sera against B.1.617.2 to be more plausible compared to B.1.351 and B.1.1.248-convalescent sera. Sera was collected from individuals infected with B.1.1.7, B.1.351, and B.1.1.248 in UK, South Africa, and Brazil respectively. The neutralization activity of these sera was tested against the B.1.617.2 native virus, B.1.617.1 pseudoviruses, and the Victoria isolate WT strain. Reduced neutralization titers were observed for all tested variants, compared to WT. However, the B.1.1.7-convalsecent sera compared to other sera gave some level of cross-protection against infection by both B.1.617.1 and B.1.617.2 variants. This suggests that individuals infected with B.1.351 and B.1.1.248 variants may be at risk of reinfection with B.1.617.2 variant compared to individuals infected with B.1.1.7 variant (Liu et al., 2021a).

As the search for neutralizing antibodies quickly arose to retaliate against the pandemic, due to the drastic immune reactions observed in the lung tissues together with the cytokine storm syndrome, some focus was given to repurposing and testing antiviral drugs found to have antiviral activity in cell culture experiments (Kiani et al., 2021). Cytokines with known antiviral effect including interferons were also evaluated (Haji Abdolvahab et al., 2021). With the urgency of the pandemic, early efforts were also focused on testing already known antiviral drugs against COVID-19. A large number of these drugs including chloroquine, ribavirin, interferons, and lopinavir/ritonavir were found to have some antiviral activity against SARS-CoV-2 (Cao et al., 2020; Gautret et al., 2020; Khalili et al., 2020; Haji Abdolvahab et al., 2021). The pharmaceutical establishments unleashed an unprecedented effort to find safe and effective treatment strategies against this pandemic and within a year, the antiviral drug, remdesivir was approved and authorized by the FDA to be used as treat- ment against COVID-19 (Eastman et al., 2020). Moreover, in their recent study using pseudotyped viruses, Hoffmann et al. (2021a) showed that the entry of all variants into human cells is susceptible to inhibition by entry inhibitors including soluble ACE2, Camostat, EK-1, and EK-1-C4. This result was equally obtained for B.1.617 pseudotyped viruses whose entry into Caco-2 cell was blocked by soluble ACE2 and Camostat similar to WT pseudotyped viruses (Hoffmann et al., 2021b). Therefore, alongside the use of neutralizing antibodies and vaccines, inhibitors targeting the RBD and proteolytic activation of the $\mathrm{S}$ protein can be used.

\section{Vaccine}

Ideally, retaliating against a viral infection will entail production of effective neutralizing antibodies that could be produced by patient or mAbs as discussed above. It is greatly important that the non-infected population which are potential targets to SARS-CoV-2 virus be immunized via vaccination in order to limit, eventually halt the spreading of the virus. Upon publication of SARS-CoV-2 genome sequence, researchers and companies set out to quickly develop a vaccine against this virus (Poland et al., 2020; Kyriakidis et al., 2021). As depicted in literature, the main routes pursued involve the use of viral antigens as vaccines for induction of neutralizing antibodies, mostly against the $\mathrm{S}$ protein to preventing infection (Krammer, 2020). Another route involves the use of vaccine strategies to favor induction of T-cell mediated immune responses and finally vaccine strategies making use of whole virus particles route (attenuated or inactivated) to induce broader polyclonal responses against several viral antigens (Jeyanathan et al., 2020; Kyriakidis et al., 2021). The elucidation of immune responses against the virus has allowed for the development of vaccine strategies which include nucleic acid (RNA based) vaccines, non-replicating virus vector, inactivated pathogen, and protein subunit (Nkengasong, 2020; Yin et al., 2020; Awadasseid et al., 2021; Ura et al., 2021).

The current nucleic acid vaccines which are RNA based, involves injecting mRNA encoding $\mathrm{S}$ protein and allowing host cell machinery to prepare the $\mathrm{S}$ protein via translation. The two mRNA FDA approved vaccines include BNT162b2 by BioNTech/Pfizer and mRNA-1273 by Moderna. BNT162b2 Pfizer vaccine is a lipid nanoparticle (LNP)-formulated nucleoside-modified RNA vaccine that encodes the stabilized prefusion SARS-CoV-2 full-length S protein. The mRNA1273 is a new LNP-encapsulated mRNA-based vaccine that consists of prefusion-stabilized full-length S protein of SARSCoV-2 (Jackson et al., 2020). The administered mRNA triggers a localized and transient inflammation after intramuscular injection, which recruits immune cells including neutrophils, monocytes, and dendritic cells (DCs). After uptake of mRNAs and efficient translation by monocytes and DCs, the viral proteins disseminate and the cells migrate to the draining lymph nodes for antigen presentation to the Tlymphocytes (Cagigi and Loré, 2021; Verbeke et al., 2021). The encoded viral antigen is also directly recognized by B lymphocytes of the host, thereby initiating an adaptive immune response directed against the $\mathrm{S}$ protein of the virus (Kyriakidis et al., 2021). Post-vaccination sera from randomly injected 
patients with either BNT162b2 vaccine or placebo, was reported to be $95 \%$ effective in preventing COVID-19 (90.3 to 97.6 with $95 \%$ Confidence Interval) irrespective of age, sex, race, ethnicity, baseline body-mass index, and the presence of coexisting conditions (Sahin et al., 2020). The incidence of adverse event was low and similar in both groups. Equivalently, eight weeks after second injection of mRNA-1273 Moderna or BNT162b2 Pfizer vaccines in a cohort of 20 volunteers, high levels of IgM and IgG anti-S protein were observed and high binding titer to the RBD was reported (Wang et al., 2021d). This neutralizing activity was found to be similar with neutralization of plasma from patients who recovered naturally from COVID-19 infection (Baden et al., 2021; Wang et al., 2021d; Weinreich et al., 2021). Consequently, these results clearly show the positive impact of this vaccine against the SARS-CoV-2 virus and therefore immunization made possible for the non-infected population. However, the efficacy of these vaccines against the variant is reported to decrease compared to the WT. At least 14 or 28 days after Ad26.COV2.S administration, an efficacy of 66.9\% (adjusted $95 \%$ confidence interval [CI], 59.0\% to $73.4 \%$ ) and $66.1 \%$ (adjusted $95 \%$ CI, $55.0 \%$ to $74.8 \%$ ) respectively, was observed for moderate to severe COVID-19 conditions. Ad26.COV2.S is a recombinant, replication-incompetent adenovirus serotype 26 (Ad26) vector encoding a full-length and stabilized SARS-CoV-2 S protein (Sadoff et al., 2021). The efficacy of Ad26.COV2.S was found to be higher for severe to critical COVID-19 conditions with efficacies of $76.7 \%$ (adjusted $95 \%$ CI, $54.6 \%$ to $89.1 \%$ ) and $85.4 \%$ (adjusted 95\% CI, 54.2 to 96.9) for least 14 or 28 days post administration respectively (Sadoff et al., 2021). This suggest a possible boosting function of the vaccine whereby in severe to critical conditions, the patient's immunity is fully in alert. In addition Ad26.COV2.S induces antibodies with Fc-mediated functions which are very potent for immune response against SARS-CoV-2 in humans (Stephenson et al., 2021).

Out of 29 BNT162b2 Pfizer vaccine-elicited sera showing neutralizing activity against the WT S protein after first and second dose of administration, 20 sera showed reduced neutralization titers against B.1.1.7 variant with 3.2-fold and 1.9-fold changes respectively (Polack et al., 2020; Collier et al., 2021; Muik et al., 2021). Moreover, pseudotyped viruses carrying the set of B.1.1.7 S mutations evaluated with sera from individuals who received two doses of BNT162b2 vaccine or mRNA-1273 vaccine (two doses) exhibited a modest reduction in neutralization titers (Collier et al., 2021). While the neutralizing activity of sera from inactivated whole-virion SARS-CoV-2 vaccine BBV152 (COVAXIN from Bharact Biotech) against B.1.1.7 variant strain was reported to stay potentially preserved, the neutralization titers of ChAdOx1 nCoV-19 (Oxford-AstraZeneca) post-vaccination sera were nine times lower than titers against the B.1.1.7 lineage relative to non-B.1.1.7 lineage in vitro (Emary et al., 2021; Sapkal et al., 2021). BBV152 is a whole-virion inactivated SARSCoV-2 vaccine formulated with a toll-like receptor (TLR) 7/8 agonist molecule adsorbed to alum (Algel-IMDG) or alum (Algel) from Bharact Biotech. While the imidazoquinoline molecule, which is a TLR 7/8 agonist, stimulates cell-mediated responses, the Algel-IMDG (an imidazoquinoline molecule chemisorbed on alum [Algel]) traffics vaccine antigen di- rectly to draining lymph nodes without diffusing into the systemic circulation (Ella et al., 2021). The Oxford-AstraZeneca vaccine is a carrier vaccine, made from a modified version of a harmless adenovirus as a shell to carry genetic code of the $S$ proteins to the cells (similar to a Trojan Horse). Once in the cells, the cells produce $S$ protein to train the body's immune system, which creates antibodies and memory cells to protect against an actual SARS-CoV-2 infection (Mahase, 2021). A recent study revealed that albeit the reduced neutralization effect, the efficacy of BNT162b2 and ChAdOx1 nCoV-19 vaccine after administration of 2 doses, is $88.0 \%$ (95\% CI, 85.3 to 90.1 ) and $67.0 \%$ (95\% CI, 61.3 to 71.8 ) respectively. Therefore, the reduced neutralization of the vaccine by the variant does not affect the effective protection by the vaccine against infection (Lopez Bernal et al., 2021). A two-dose regimen of NVX-CoV2373 (Novavax -a proteinbased subunit vaccine) and placebo, given 21 days apart randomly to 15,187 participants, was found to be safe and $89.7 \%$ effective against prototype and B.1.1.7 variants (Heath et al., 2021). NVX-CoV2373 is a protein adjuvant, which contains the $\mathrm{S}$ protein formulated as a nanoparticle, that is not antigenic. When the vaccine is injected, it stimulates the immune system to produce antibodies and T-cell immune activation (Tian et al., 2021). The UK phase 3 clinical trials of NVXCoV2373 via polymerase chain reaction performed on strains from 56 of 62 COVID-19 cases, reported a vaccine efficacy of $85.6 \%$ against B.1.1.7 variant (Bian et al., 2021). All these results cheerily indicate that B.1.1.7 variant is unlikely to be a major concern for current vaccines or for an increased risk of reinfection.

As mentioned earlier, the presence of the E484K mutation in the B.1.351 variant can account for reports that indicate immune escape from convalescent sera samples and reduced neutralizing activity with post-vaccination sera samples. The post-hoc sera obtained from 12 participants who received the inactivated vaccine BBIBP-CorV (Sinopharm) showed a slight reduction (less than two-fold) in neutralizing activity against the B.1.351 variant (Huang et al., 2021). Also, a randomized placebo-controlled trial in South Africa reported vaccine efficacy of SARS-CoV-2 nanoparticle vaccine (NVXCoV2373) against B.1.351 to be about $51 \%$ with mild to moderate reactogenicity, suggesting incomplete immune escape with possibly delay disease progression (Madhi et al., 2021). Similarly, another study reported an efficacy of $49.4 \%$ (95\% CI: 6.172.8) for B.1.351 variant compared to the original SARS-CoV-2 strain, in a South Africa phase $2 \mathrm{~b}$ clinical trial (Bian et al., 2021). The plasma obtained from BNT162b2 vaccinated individuals showed a significant decrease against pseudotyped viruses with E484K+N501Y or K417N + E484K + N501Y mutations (Wang et al., 2021d; Xie et al., 2021). While fold reductions in neutralization were observed with the above-mentioned vaccines, major if not complete immune escape was reported for AZD1222 (Madhi et al., 2021). Recently, three sub-lineages emerging from the B.1.351 variant were reported. These B.1.351 sublineages were exposed to post-vaccination sera from individuals who received two doses of either the BNT162b2 vaccine $(n=30)$ or the mRNA1273 vaccine $(n=35)$. The neutralizing activities were reduced significantly ranging from 34 -fold to 42 -fold (BNT162b2) and 19.2-fold to 27.7-fold (mRNA-1273) (Harvey et al., 2021). 
The ability of this variant to escape natural-induced and vaccine-induced immunity leading to reduced neutralizing activity gradually molds doubt about the efficacy of vaccines to bring to a halt COVID-19.

A recent study showed that older people (about 80 years and above) infected with the B.1.1.248 variant when administered the BNT162b2 vaccine generated a robust humoral immune response even though the neutralization efficacy was reduced (Parry et al., 2021). This points out the possible exclusion of this high-risk group from the list of those vulnerable to reinfection and to some degree boosting of their immune response. Another study showed that the sera of mRNA-1273 and BNT162b2 vaccines had a reduced neutralization against B.1.1.248 compared to the Wuhan strain (Wang et al., 2021a). Strikingly, the B.1.1.248 variant was reported to be less resistant to the neutralizing activities of convalescent sera of BNT162b2 and ChAdOx1 nCoV-19 vaccine similarly with the resistance of the B.1.1.7 variant (Dejnirattisai et al., 2021; Focosi et al., 2021). When CoronaVac (Sinovac COVID-19 vaccine-inactivated virus vaccine) was administered to symptomatic COVID-19 patients in a B.1.1.248 epidemic setting, vaccine effectiveness against symptomatic SARS-CoV-2 infection was observed (Hitchings et al., 2021). These preprint results hereby suggest that B.1.1.248 variant possibly can be neutralized by CoronaVac although its neutralizing efficacy is still not clear.

The novel SARS-CoV-2 variant, B.1.427/B.1.429 that emerged in Southern California was assessed for neutralizing antibody responses following natural infection or mRNA vaccination. Pseudotyped viruses expressing the WT or the B.1.427/ B.1.429 S protein were exposed to convalescent plasma, Moderna mRNA-1273, and Pfizer/BioNtech BNT162b2 vaccineelicited sera (McCallum et al., 2021a). The neutralization titers were reduced by 4.9-fold and 3-6 folds respectively, relative to WT pseudotyped virus. An attempted explanation suggests that there is a large structural rearrangement of the NTD antigenic site involving the S13I and W152C mutations thus abolishing binding of the mAbs. Also the L452R mutation at the RBD site could be responsible for escape from certain RBD targeting mAbs (McCallum et al., 2021a). Similar conclusion of reduced neutralizing activity was reported in a study that used post-vaccinated sera from patients vaccinated with two doses of Pfizer BNT16b2 or Moderna mRNA1273 vaccine. The results showed that a two-fold decrease in neutralization titer was observed from vaccinated patients (Deng et al., 2021).

The sera from individuals vaccinated with Pfizer BNT162b2 and Moderna mRNA-1273 vaccines when incubated with pseudotyped viruses bearing B.1.617 and B.1.618 S protein showed a 4-fold and 2.7-fold resistance to neutralization compared to WT respectively (Tada et al., 2021). Similarly, cell entry driven by S protein of the B.1.617 pseudotyped virus was inhibited by BNT162b2-elicited sera 3-fold less efficiently compared to WT when inoculated onto Vero cells (Hoffmann et al., 2021b). The lineage B.1.617 splits further into the subtypes B.1.617.1, B.1.617.2, and B.1.617.3. A recent study showed that the pseudotyped virus bearing the B.1.617.1 mutation exhibited $\mathrm{PRNT}_{50}$ (50\% plaque reduction neutralization) values 0.31 times the $\mathrm{PRNT}_{50}$ values of the $\mathrm{WT}$ when exposed to BNT162b2-elicited sera drawn 2 to 4 weeks after second dose administration (Liu et al., 2021b). Another study showed that the B.1.617.1 variant was 6.8-fold less susceptible to neutralization by BNT162b2-elicited sera and mRNA-1273-elicited sera compared to WT. Despite the reduced neutralization, a majority of the sera from vaccinated individuals were still able to neutralize the B.1.617.1 variant, suggesting protective immunity by the mRNA vaccines tested here are likely retained against the B.1.617.1 variant (Edara et al., 2021). Recently, a study also reported a 2.7-fold and 2.6-fold reduction in neutralizing activity of Pfizer-BioNTech and Oxford-AstraZeneca vaccine-elicited sera against B.1.617.1 pseudotyped viruses respectively. In a similar way, B.1.617.2 variant inhibited neutralization by 2.5 -fold and 4.5 -fold respectively (Liu et al., 2021a). In effect, for this study, the sera from a pool of 25 individuals immunized with Pfizer-BioNTech or Oxford-AstraZeneca (ChAdOx1 nCoV-19) vaccine, was collected 7-17 days or 14/28 days respectively, after second dose of administration (Liu et al., 2021a). Planas et al. (2021) confirmed the resistance of B.1.617.2 variant to Pfizer-BioNTech (3-6-fold reduction of neutralization) or Oxford-AstraZeneca vaccine-elicited sera (almost complete inhibition of neutralization) (Planas et al., 2021). When two doses of BNT162b2 and ChAdOx1 nCoV-19 vaccine were administered to persons with the B.1.617.2 variant, efficacies of $88.0 \%$ (95\% CI, 85.3 to 90.1 ) and $67.0 \%$ (95\% CI, 61.3 to 71.8) were reported respectively (Lopez Bernal et al., 2021). BBV152 (Covaxin) vaccine was reported to show an efficacy of $88.48 \%$ (95\% CI: $62.02 \%$ to $126.2 \%$ ) against the B.1.617 variant. In this study, convalescent sera samples were collected from vaccine recipients and used to perform $\mathrm{PRNT}_{50}$ against B.1.617 variant (Yadav et al., 2021). All together, these data suggest that protective immunity by vaccines currently in use would provide some protection against the current generation of B.1.617 variant although the reduced neutralization activity.

\section{Concluding Remarks}

The fast and sudden surge of SARS-CoV-2 variants continues to challenge existing attempts to curb the pandemic. At the current pace of the pandemic, special attention must be given to the elaboration of monoclonal antibody therapy and vaccine strategies especially with the rapid growth, spread or transmission, and dominant establishment of the variants across the globe. Majority of variants have been reported to be refractory to neutralization and as such escape immunity by antibodies. In addition, more studies are needed to identify the various mutations which are responsible for the various phenotypes observed in variants. Insights on the life cycle and pathogenesis of these variants will allow for better management and eventually a halt of the pandemic. Development of potent, possibly polyvalent mAbs and effective broad-spectrum vaccines against variants most especially the upcoming variants will be major contributing steps towards this goal. In this review, we summarized the recent reports on SARS$\mathrm{CoV}-2$ progression most especially its emerging and becoming dominant variants in relation to their transmission and response to monoclonal antibody therapy and vaccines. 


\section{Acknowledgements}

This work was supported by the National Research Foundation of Korea (NRF), grant number 2020M3A9I2081695, 2018M3A9H4089656, and 2021R1A4A1028969 (to H.R.L). Due to immune space limitations, we sincerely apologize for not being able to cite all papers related to this topic.

\section{Conflict of Interest}

The authors have no conflict of interest to report.

\section{References}

Abdool Karim, S.S. and de Oliveira, T. 2021. New SARS-CoV-2 variants - clinical, public health, and vaccine implications. $N$. Engl. J. Med. 384, 1866-1868.

Ali, F., Kasry, A., and Amin, M. 2021. The new SARS-CoV-2 strain shows a stronger binding affinity to ACE2 due to N501Y mutant. Med. Drug Discov. 10, 100086.

Astuti, I. and Ysrafil. 2020. Severe acute respiratory syndrome coronavirus 2 (SARS-CoV-2): an overview of viral structure and host response. Diabetes Metab. Syndr. 14, 407-412.

Awadasseid, A., Wu, Y., Tanaka, Y., and Zhang, W. 2021. Current advances in the development of SARS-CoV-2 vaccines. Int. J. Biol. Sci. 17, 8-19.

Baden, L.R., El Sahly, H.M., Essink, B., Kotloff, K., Frey, S., Novak, R., Diemert, D., Spector, S.A., Rouphael, N., Creech, C.B., et al. 2021. Efficacy and safety of the mRNA-1273 SARS-CoV-2 vaccine. $N$. Engl. J. Med. 384, 403-416.

Bayati, A., Kumar, R., Francis, V., and McPherson, P.S. 2021. SARSCoV-2 infects cells after viral entry via clathrin-mediated endocytosis. J. Biol. Chem. 296, 100306.

Bestle, D., Heindl, M.R., Limburg, H., Van Lam van, T., Pilgram, O., Moulton, H., Stein, D.A., Hardes, K., Eickmann, M., Dolnik, O., et al. 2020. TMPRSS2 and furin are both essential for proteolytic activation of SARS-CoV-2 in human airway cells. Life Sci. Alliance 3, e202000786.

Bian, L., Gao, F., Zhang, J., He, Q., Mao, Q., Xu, M., and Liang, Z. 2021. Effects of SARS-CoV-2 variants on vaccine efficacy and response strategies. Expert Rev. Vaccines 20, 365-373.

Boehm, E., Kronig, I., Neher, R.A., Eckerle, I., Vetter, P., Kaiser, L., and Geneva Centre for Emerging Viral Diseases. 2021. Novel SARS-CoV-2 variants: the pandemics within the pandemic. Clin. Microbiol. Infect. 27, P1109-P1117.

Cagigi, A. and Loré, K. 2021. Immune responses induced by mRNA vaccination in mice, monkeys and humans. Vaccines 9, 61 .

Cao, B., Wang, Y., Wen, D., Liu, W., Wang, J., Fan, G., Ruan, L., Song, B., Cai, Y., Wei, M., et al. 2020. A trial of lopinavir-ritonavir in adults hospitalized with severe Covid-19. N. Engl. J. Med. 382, 1787-1799.

Cele, S., Gazy, I., Jackson, L., Hwa, S.H., Tegally, H., Lustig, G., Giandhari, J., Pillay, S., Wilkinson, E., Naidoo, Y., et al. 2021. Escape of SARS-CoV-2 501Y.V2 from neutralization by convalescent plasma. Nature 593, 142-146.

Chakravarty, D., Nair, S.S., Hammouda, N., Ratnani, P., Gharib, Y., Wagaskar, V., Mohamed, N., Lundon, D., Dovey, Z., Kyprianou, N., et al. 2020. Sex differences in SARS-CoV-2 infection rates and the potential link to prostate cancer. Commun. Biol. 3, 374.

Chan, J.F.W., Kok, K.H., Zhu, Z., Chu, H., To, K.K.W., Yuan, S., and Yuen, K.Y. 2020. Genomic characterization of the 2019 novel human-pathogenic coronavirus isolated from a patient with atypical pneumonia after visiting Wuhan. Emerg. Microbes Infect.
9, 221-236.

Chen, J., Wang, R., Wang, M., and Wei, G.W. 2020. Mutations strengthened SARS-CoV-2 infectivity. J. Mol. Biol. 432, 5212-5226.

Collier, D.A., De Marco, A., Ferreira, I.A.T.M., Meng, B., Datir, R.P., Walls, A.C., Kemp, S.A., Bassi, J., Pinto, D., Silacci-Fregni, C., et al. 2021. Sensitivity of SARS-CoV-2 B.1.1.7 to mRNA vaccine-elicited antibodies. Nature 593, 136-141.

Coperchini, F., Chiovato, L., Croce, L., Magri, F., and Rotondi, M. 2020. The cytokine storm in COVID-19: an overview of the involvement of the chemokine/chemokine-receptor system. Cytokine Growth Factor Rev. 53, 25-32.

Coutard, B., Valle, C., de Lamballerie, X., Canard, B., Seidah, N.G., and Decroly, E. 2020. The spike glycoprotein of the new coronavirus 2019-nCoV contains a furin-like cleavage site absent in CoV of the same clade. Antiviral Res. 176, 104742.

DeFrancesco, L. 2020. COVID-19 antibodies on trial. Nat. Biotechnol. 38, 1242-1252.

Dejnirattisai, W., Zhou, D., Supasa, P., Liu, C., Mentzer, A.J., Ginn, H.M., Zhao, Y., Duyvesteyn, H.M.E., Tuekprakhon, A., Nutalai, R., et al. 2021. Antibody evasion by the P.1 strain of SARS-CoV-2. Cell 184, 2939-2954.

Deng, X., Garcia-Knight, M.A., Khalid, M.M., Servellita, V., Wang, C., Morris, M.K., Sotomayor-González, A., Glasner, D.R., Reyes, K.R., Gliwa, A.S., et al. 2021. Transmission, infectivity, and antibody neutralization of an emerging SARS-CoV-2 variant in California carrying a L452R spike protein mutation. medRxiv. doi: https://doi.org/10.1101/2021.03.07.21252647.

Eastman, R.T., Roth, J.S., Brimacombe, K.R., Simeonov, A., Shen, M., Patnaik, S., and Hall, M.D. 2020. Remdesivir: a review of its discovery and development leading to emergency use authorization for treatment of COVID-19. ACS Cent. Sci. 6, 672-683.

Edara, V.V., Pinsky, B.A., Suthar, M.S., Lai, L., Davis-Gardner, M.E., Floyd, K., Flowers, M.W., Wrammert, J., Hussaini, L., Ciric, C.R., et al. 2021. Infection and vaccine-induced neutralizing-antibody responses to the SARS-CoV-2 B.1.617 variants. N. Engl. J. Med. 385, 664-666.

Ella, R., Vadrevu, K.M., Jogdand, H., Prasad, S., Reddy, S., Sarangi, V., Ganneru, B., Sapkal, G., Yadav, P., Abraham, P., et al. 2021. Safety and immunogenicity of an inactivated SARS-CoV-2 vaccine, BBV152: a double-blind, randomised, phase 1 trial. Lancet Infect. Dis. 21, 637-646.

Emary, K.R.W., Golubchik, T., Aley, P.K., Ariani, C.V., Angus, B., Bibi, S., Blane, B., Bonsall, D., Cicconi, P., Charlton, S., et al. 2021. Efficacy of ChAdOx1 nCoV-19 (AZD1222) vaccine against SARSCoV-2 variant of concern 202012/01 (B.1.1.7): an exploratory analysis of a randomised controlled trial. Lancet 397, 1351-1362.

Faria, N.R., Mellan, T.A., Whittaker, C., Claro, I.M., Candido, D.d.S., Mishra, S., Crispim, M.A.E., Sales, F.C.S., Hawryluk, I., McCrone, J.T., et al. 2021. Genomics and epidemiology of the P.1 SARSCoV-2 lineage in Manaus, Brazil. Science 372, 815-821.

Fathi, N. and Rezaei, N. 2020. Lymphopenia in COVID-19: Therapeutic opportunities. Cell Biol. Int. 44, 1792-1797.

Fehr, A.R. and Perlman, S. 2015. Coronaviruses: an overview of their replication and pathogenesis. In Maier, H., Bickerton, E., and Britton, P. (eds.), Coronaviruses. Methods in Molecular Biology, vol. 1282, Humana Press, New York, USA.

Focosi, D., Tuccori, M., Baj, A., and Maggi, F. 2021. SARS-CoV-2 variants: a synopsis of in vitro efficacy data of convalescent plasma, currently marketed vaccines, and monoclonal antibodies. Viruses 13, 1211

Gao, Y.M., Xu, G., Wang, B., and Liu, B.C. 2021. Cytokine storm syndrome in coronavirus disease 2019: A narrative review. J. Intern. Med. 289, 147-161.

Gao, S. and Zhang, L. 2020. ACE2 partially dictates the host range and tropism of SARS-CoV-2. Comput. Struct. Biotechnol. J. 18, 4040-4047.

Garcia-Beltran, W.F., Lam, E.C., Astudillo, M.G., Yang, D., Miller, 
T.E., Feldman, J., Hauser, B.M., Caradonna, T.M., Clayton, K.L., Nitido, A.D., et al. 2021. COVID-19-neutralizing antibodies predict disease severity and survival. Cell 184, 476-488.

Gautret, P., Lagier, J.C., Parola, P., Hoang, V.T., Meddeb, L., Mailhe, M., Doudier, B., Courjon, J., Giordanengo, V., Vieira, V.E., et al. 2020. Hydroxychloroquine and azithromycin as a treatment of COVID-19: results of an open-label non-randomized clinical trial. Int. J. Antimicrob. Agents 56, 105949.

Gheblawi, M., Wang, K., Viveiros, A., Nguyen, Q., Zhong, J.-C., Turner, A.J., Raizada, M.K., Grant, M.B., and Oudit, G.Y. 2020 Angiotensin-converting enzyme 2: SARS-CoV-2 receptor and regulator of the renin-angiotensin system. Circ. Res. 126, 14561474.

Glowacka, I., Bertram, S., Herzog, P., Pfefferle, S., Steffen, I., Muench, M.O., Simmons, G., Hofmann, H., Kuri, T., Weber, F., et al. 2010. Differential downregulation of ACE2 by the spike proteins of severe acute respiratory syndrome coronavirus and human coronavirus NL63. J. Virol. 84, 1198-1205.

Gottlieb, R.L., Nirula, A., Chen, P., Boscia, J., Heller, B., Morris, J., Huhn, G., Cardona, J., Mocherla, B., Stosor, V., et al. 2021. Effect of bamlanivimab as monotherapy or in combination with Etesevimab on viral load in patients with mild to moderate COVID-19. JAMA 325, 632-644.

Gralinski, L.E. and Menachery, V.D. 2020. Return of the coronavirus: 2019-nCoV. Viruses 12, 135.

Greaney, A.J., Loes, A.N., Crawford, K.H.D., Starr, T.N., Malone, K.D., Chu, H.Y., and Bloom, J.D. 2021. Comprehensive mapping of mutations in the SARS-CoV-2 receptor-binding domain that affect recognition by polyclonal human plasma antibodies. Cell Host Microbe 29, 463-476.

Haji Abdolvahab, M., Moradi-kalbolandi, S., Zarei, M., Bose, D., Majidzadeh-A, K., and Farahmand, L. 2021. Potential role of interferons in treating COVID-19 patients. Int. Immunopharmacol. 90, 107171

Hamed, S.M., Elkhatib, W.F., Khairalla, A.S., and Noreddin, A.M. 2021. Global dynamics of SARS-CoV-2 clades and their relation to COVID-19 epidemiology. Sci. Rep. 11, 8435.

Han, Q., Lin, Q., Jin, S., and You, L. 2020. Coronavirus 2019-nCoV: a brief perspective from the front line. J. Infect. 80, 373-377.

Hansen, J., Baum, A., Pascal, K.E., Russo, V., Giordano, S., Wloga, E., Fulton, B.O., Yan, Y., Koon, K., Patel, K., et al. 2020. Studies in humanized mice and convalescent humans yield a SARS-CoV-2 antibody cocktail. Science 369, 1010-1014.

Harvey, W.T., Carabelli, A.M., Jackson, B., Gupta, R.K., Thomson, E.C., Harrison, E.M., Ludden, C., Reeve, R., Rambaut, A., Peacock, S.J., et al. 2021. SARS-CoV-2 variants, spike mutations and immune escape. Nat. Rev. Microbiol. 19, 409-424.

Heath, P.T., Galiza, E.P., Baxter, D.N., Boffito, M., Browne, D., Burns, F., Chadwick, D.R., Clark, R., Cosgrove, C., Galloway, J., et al. 2021. Efficacy of the NVX-CoV2373 covid-19 vaccine against the B.1.1.7 variant. N. Engl. J. Med. doi: 10.1056/NEJMoa2107659.

Hitchings, M.D.T., Ranzani, O.T., Scaramuzzini Torres, M.S., de Oliveira, S.B., Almiron, M., Said, R., Borg, R., Schulz, W.L., de Oliveira, R.D., da Silva, P.V., et al. 2021. Effectiveness of CoronaVac in the setting of high SARS-CoV-2 P.1 variant transmission in Brazil: a test-negative case-control study. medRxiv. doi: https://doi.org/ 10.1101/2021.04.07.21255081.

Hoffmann, M., Arora, P., Groß, R., Seidel, A., Hörnich, B.F., Hahn, A.S., Krüger, N., Graichen, L., Hofmann-Winkler, H., Kempf, A., et al. 2021a. SARS-CoV-2 variants B.1.351 and P.1 escape from neutralizing antibodies. Cell 184, 2384-2393.

Hoffmann, M., Hofmann-Winkler, H., Krüger, N., Kempf, A., Nehlmeier, I., Graichen, L., Arora, P., Sidarovich, A., Moldenhauer, A.S., Winkler, M.S., et al. 2021b. SARS-CoV-2 variant B.1.617 is resistant to bamlanivimab and evades antibodies induced by infection and vaccination. Cell Rep. 36, 109415.

Huang, B., Dai, L., Wang, H., Hu, Z., Yang, X., Tan, W., and Gao,
G.F. 2021. Neutralization of SARS-CoV-2 VOC 501Y.V2 by human antisera elicited by both inactivated BBIBP-CorV and recombinant dimeric RBD ZF2001 vaccines. bioRxiv, doi: https://doi.org/10.1101/2021.02.01.429069.

Hui, K.P.Y., Cheung, M.C., Perera, R.A.P.M., Ng, K.C., Bui, C.H.T., Ho, J.C.W., Ng, M.M.T., Kuok, D.I.T., Shih, K.C., Tsao, S.W., et al. 2020. Tropism, replication competence, and innate immune responses of the coronavirus SARS-CoV-2 in human respiratory tract and conjunctiva: an analysis in ex-vivo and in-vitro cultures. Lancet Respir. Med. 8, 687-695.

Ivanov, K.A., Thiel, V., Dobbe, J.C., van der Meer, Y., Snijder, E.J., and Ziebuhr, J. 2004. Multiple enzymatic activities associated with severe acute respiratory syndrome coronavirus helicase. $J$. Virol. 78, 5619-5632.

Jackson, L.A., Anderson, E.J., Rouphael, N.G., Roberts, P.C., Makhene, M., Coler, R.N., McCullough, M.P., Chappell, J.D., Denison, M.R., Stevens, L.J., et al. 2020. An mRNA vaccine against SARS-CoV-2 - preliminary report. N. Engl. J. Med. 383, 1920-1931.

Jeyanathan, M., Afkhami, S., Smaill, F., Miller, M.S., Lichty, B.D., and Xing, Z. 2020. Immunological considerations for COVID-19 vaccine strategies. Nat. Rev. Immunol. 20, 615-632.

Jiang, S., Zhang, X., Yang, Y., Hotez, P.J., and Du, L. 2020. Neutralizing antibodies for the treatment of COVID-19. Nat. Biomed. Eng. 4, 1134-1139.

Juraszek, J., Rutten, L., Blokland, S., Bouchier, P., Voorzaat, R., Ritschel, T., Bakkers, M.J.G., Renault, L.L.R., and Langedijk, J.P.M. 2021. Stabilizing the closed SARS-CoV-2 spike trimer. Nat. Commun. 12, 244.

Khalili, J.S., Zhu, H., Mak, N.S.A., Yan, Y., and Zhu, Y. 2020. Novel coronavirus treatment with ribavirin: groundwork for an evaluation concerning COVID-19. J. Med. Virol. 92, 740-746.

Kiani, P., Scholey, A., Dahl, T.A., McMann, L., Iversen, J.M., and Verster, J.C. 2021. In vitro assessment of the antiviral activity of ketotifen, indomethacin and naproxen, alone and in combination, against SARS-CoV-2. Viruses 13, 558.

Kim, Y.J., Jang, U.S., Soh, S.M., Lee, J.Y., and Lee, H.R. 2021. The impact on infectivity and neutralization efficiency of SARS-CoV-2 lineage B.1.351 Pseudovirus. Viruses 13, 633.

Kirchdoerfer, R.N. and Ward, A.B. 2019. Structure of the SARS-CoV nsp12 polymerase bound to nsp7 and nsp 8 co-factors. Nat. Commun. 10, 2342.

Koyama, T., Platt, D., and Parida, L. 2020. Variant analysis of SARSCoV-2 genomes. Bull. World Health Organ. 98, 495-504.

Krammer, F. 2020. SARS-CoV-2 vaccines in development. Nature 586, 516-527.

Kyriakidis, N.C., López-Cortés, A., González, E.V., Grimaldos, A.B., and Prado, E.O. 2021. SARS-CoV-2 vaccines strategies: a comprehensive review of phase 3 candidates. npj Vaccines 6, 28.

La Rosa, G., Mancini, P., Bonanno Ferraro, G., Veneri, C., Iaconelli, M., Lucentini, L., Bonadonna, L., Brusaferro, S., Brandtner, D., Fasanella, A., et al. 2021. Rapid screening for SARS-CoV-2 variants of concern in clinical and environmental samples using nested RT-PCR assays targeting key mutations of the spike protein. Water Res. 197, 117104.

Li, X., Geng, M., Peng, Y., Meng, L., and Lu, S. 2020. Molecular immune pathogenesis and diagnosis of COVID-19. J. Pharm. Anal. 10, 102-108.

Lippi, G., Sanchis-Gomar, F., and Henry, B.M. 2020. COVID-19: unravelling the clinical progression of nature's virtually perfect biological weapon. Ann. Transl. Med. 8, 693.

Liu, C., Ginn, H.M., Dejnirattisai, W., Supasa, P., Wang, B., Tuekprakhon, A., Nutalai, R., Zhou, D., Mentzer, A.J., Zhao, Y., et al. 2021a. Reduced neutralization of SARS-CoV-2 B.1.617 by vaccine and convalescent serum. Cell 184, 4220-4236.

Liu, J., Liu, Y., Xia, H., Zou, J., Weaver, S.C., Swanson, K.A., Cai, H., Cutler, M., Cooper, D., Muik, A., et al. 2021b. BNT162b2-elicited neutralization of B.1.617 and other SARS-CoV-2 variants. 
Nature 596, 273-275.

Liu, H., Wei, P., Zhang, Q., Chen, Z., Aviszus, K., Downing, W., Peterson, S., Reynoso, L., Downey, G.P., Frankel, S.K., et al. 2021c. 501Y.V2 and 501Y.V3 variants of SARS-CoV-2 lose binding to bamlanivimab in vitro. $m A$ bs 13, 1919285.

Lloyd, E.C., Gandhi, T.N., and Petty, L.A. 2021. Monoclonal antibodies for COVID-19. JAMA 325, 1015.

Lopez Bernal, J., Andrews, N., Gower, C., Gallagher, E., Simmons, R., Thelwall, S., Stowe, J., Tessier, E., Groves, N., Dabrera, G., et al. 2021. Effectiveness of Covid-19 vaccines against the B.1.617.2 (Delta) variant. N. Engl. J. Med. 385, 585-594.

Luan, B., Wang, H., and Huynh, T. 2021. Enhanced binding of the N501Y-mutated SARS-CoV-2 spike protein to the human ACE2 receptor: insights from molecular dynamics simulations. FEBS Lett. 595, 1454-1461.

Macia, E., Ehrlich, M., Massol, R., Boucrot, E., Brunner, C., and Kirchhausen, T. 2006. Dynasore, a cell-permeable inhibitor of dynamin. Dev. Cell 10, 839-850.

Madhi, S.A., Baillie, V., Cutland, C.L., Voysey, M., Koen, A.L., Fairlie, L., Padayachee, S.D., Dheda, K., Barnabas, S.L., Bhorat, Q.E., et al. 2021. Safety and efficacy of the ChAdOx1 nCoV-19 (AZD1222) Covid-19 vaccine against the B.1.351 variant in South Africa. N. Engl. J. Med. 384, 1885-1898.

Mahase, E. 2020. Covid-19: FDA authorises neutralising antibody bamlanivimab for non-admitted patients. BMJ 371, m4362.

Mahase, E. 2021. How the Oxford-AstraZeneca covid-19 vaccine was made. BMJ 372, n86.

Market, M., Angka, L., Martel, A.B., Bastin, D., Olanubi, O., Tennakoon, G., Boucher, D.M., Ng, J., Ardolino, M., and Auer, R.C. 2020. Flattening the COVID-19 curve with natural killer cell based immunotherapies. Front. Immunol. 11, 1512.

Masters, P.S. 2006. The molecular biology of coronaviruses. $A d v$. Virus Res. 66, 193-292.

McCallum, M., Bassi, J., Marco, A.D., Chen, A., Walls, A.C., Iulio, J.D., Tortorici, M.A., Navarro, M.J., Silacci-Fregni, C., Saliba, C., et al. 2021a. SARS-CoV-2 immune evasion by variant B.1.427/ B.1.429. Science 373, 648-654.

McCallum, M., Marco, A.D., Lempp, F., Tortorici, M.A., Pinto, D., Walls, A.C., Beltramello, M., Chen, A., Liu, Z., Zatta, F., et al. 2021b. N-terminal domain antigenic mapping reveals a site of vulnerability for SARS-CoV-2. Cell 184, 2332-2347.

Mercatelli, D. and Giorgi, F.M. 2020. Geographic and genomic distribution of SARS-CoV-2 mutations. Front. Microbiol. 11, 1800.

Min, L. and Sun, Q. 2021. Antibodies and vaccines target RBD of SARS-CoV-2. Front. Mol. Biosci. 8, 671633.

Mlcochova, P., Kemp, S.A., Shanker Dhar, M., Papa, G., Meng, B., Mishra, S., Whittaker, C., Mellan, T., Ferreira, I., Datir, R., et al. 2021. SARS-CoV-2 B.1.617.2 Delta variant emergence and vaccine breakthrough. bioRxiv. doi: https://doi.org/10.1101/2021. 05.08.443253.

Motozono, C., Toyoda, M., Zahradnik, J., Saito, A., Nasser, H., Tan, T.S., Ngare, I., Kimura, I., Uriu, K., Kosugi, Y., et al. 2021. SARSCoV-2 spike L452R variant evades cellular immunity and increases infectivity. Cell Host Microbe 29, 1124-1136.

Muik, A., Wallisch, A.K., Sänger, B., Swanson, K.A., Mühl, J., Chen, W., Cai, H., Maurus, D., Sarkar, R., Türeci, Ö., et al. 2021. Neutralization of SARS-CoV-2 lineage B.1.1.7 pseudovirus by BNT$162 \mathrm{~b} 2$ vaccine-elicited human sera. Science 371, 1152-1153.

Nikolich-Zugich, J., Knox, K.S., Rios, C.T., Natt, B., Bhattacharya, D., and Fain, M.J. 2020. SARS-CoV-2 and COVID-19 in older adults: what we may expect regarding pathogenesis, immune responses, and outcomes. GeroScience 42, 505-514.

Nkengasong, J. 2020. China's response to a novel coronavirus stands in stark contrast to the 2002 SARS outbreak response. Nat. Med. 26, 310-311.

Ou, J., Zhou, Z., Dai, R., Zhang, J., Zhao, S., Wu, X., Lan, W., Ren, Y., Cui, L., Lan, Q., et al. 2021. V367F mutation in SARS-CoV-2 spike RBD emerging during the early transmission phase enhances viral infectivity through increased human ACE2 receptor binding affinity. J. Virol. 95, e0061721.

Ozono, S., Zhang, Y., Ode, H., Sano, K., Tan, T.S., Imai, K., Miyoshi, K., Kishigami, S., Ueno, T., Iwatani, Y., et al. 2021. SARS-CoV-2 D614G $S$ mutation increases entry efficiency with enhanced ACE2-binding affinity. Nat. Commun. 12, 848 .

Parry, H.M., Tut, G., Faustini, S., Stephens, C., Saunders, P., Bentley, C., Hilyard, K., Brown, K., Amirthalingam, G., Charlton, S., et al. 2021. BNT162b2 vaccination in people over 80 years of age induces strong humoral immune responses with cross neutralisation of P.1 Brazilian variant. SSRN. doi: http://dx.doi.org/10.2139/ ssrn.3816840.

Picchianti Diamanti, A., Rosado, M.M., Pioli, C., Sesti, G., and Laganà, B. 2020. Cytokine release syndrome in COVID-19 patients, a new scenario for an old concern: the fragile balance between infections and autoimmunity. Int. J. Mol. Sci. 21, 3330.

Planas, D., Bruel, T., Grzelak, L., Guivel-Benhassine, F., Staropoli, I., Porrot, F., Planchais, C., Buchrieser, J., Rajah, M.M., Bishop, E., et al. 2021. Sensitivity of infectious SARS-CoV-2 B.1.1.7 and B.1.351 variants to neutralizing antibodies. Nat. Med. 27, 917924.

Poduri, R., Joshi, G., and Jagadeesh, G. 2020. Drugs targeting various stages of the SARS-CoV-2 life cycle: Exploring promising drugs for the treatment of Covid-19. Cell. Signal. 74, 109721.

Polack, F.P., Thomas, S.J., Kitchin, N., Absalon, J., Gurtman, A., Lockhart, S., Perez, J.L., Pérez Marc, G., Moreira, E.D., Zerbini, C., et al. 2020. Safety and efficacy of the BNT162b2 mRNA covid-19 vaccine. N. Engl. J. Med. 383, 2603-2615.

Poland, G.A., Ovsyannikova, I.G., Crooke, S.N., and Kennedy, R.B. 2020. SARS-CoV-2 vaccine development: current status. Mayo Clin. Proc. 95, 2172-2188.

Post, N., Eddy, D., Huntley, C., van Schalkwyk, M.C.I., Shrotri, M., Leeman, D., Rigby, S., Williams, S.V., Bermingham, W.H., Kellam, P., et al. 2020. Antibody response to SARS-CoV-2 infection in humans: A systematic review. PLoS ONE 15, e0244126.

Ragab, D., Salah Eldin, H., Taeimah, M., Khattab, R., and Salem, R. 2020. The COVID-19 cytokine storm; What we know so far. Front. Immunol. 11, 1446.

Sadoff, J., Le Gars, M., Shukarev, G., Heerwegh, D., Truyers, C., de Groot, A.M., Stoop, J., Tete, S., Van Damme, W., Leroux-Roels, I., et al. 2021. Interim results of a phase 1-2a trial of Ad26.COV2.S Covid-19 vaccine. N. Engl. J. Med. 384, 1824-1835.

Sahin, U., Muik, A., Vogler, I., Derhovanessian, E., Kranz, L.M., Vormehr, M., Quandt, J., Bidmon, N., Ulges, A., Baum, A., et al. 2020. BNT162b2 induces SARS-CoV-2-neutralising antibodies and T cells in humans. medRxiv. doi: https://doi.org/10.1101/2020.12. 09.20245175 .

Sapkal, G.N., Yadav, P.D., Ella, R., Deshpande, G.R., Sahay, R.R., Gupta, N., Mohan, V.K., Abraham, P., Panda, S., and Bhargava, B. 2021. Neutralization of UK-variant VUI-202012/01 with COVAXIN vaccinated human serum. bioRxiv. doi: https://doi.org/10.1101/ 2021.01.26.426986.

Sengupta, A., Hassan, S.S., and Choudhury, P.P. 2021. Clade GR and clade GH isolates of SARS-CoV-2 in Asia show highest amount of SNPs. Infect. Genet. Evol. 89, 104724.

Sevajol, M., Subissi, L., Decroly, E., Canard, B., and Imbert, I. 2014. Insights into RNA synthesis, capping, and proofreading mechanisms of SARS-coronavirus. Virus Res. 194, 90-99.

Shang, J., Ye, G., Shi, K., Wan, Y., Luo, C., Aihara, H., Geng, Q., Auerbach, A., and Li, F. 2020. Structural basis of receptor recognition by SARS-CoV-2. Nature 581, 221-224.

Shen, X., Tang, H., McDanal, C., Wagh, K., Fischer, W., Theiler, J., Yoon, H., Li, D., Haynes, B.F., Sanders, K.O., et al. 2021. SARSCoV-2 variant B.1.1.7 is susceptible to neutralizing antibodies elicited by ancestral spike vaccines. Cell Host Microbe 29, 529539. 
Singh, J., Samal, J., Kumar, V., Sharma, J., Agrawal, U., Ehtesham, N.Z., Sundar, D., Rahman, S.A., Hira, S., and Hasnain, S.E. 2021. Structure-function analyses of new SARS-CoV-2 variants B.1.1.7, B.1.351 and B.1.1.28.1: clinical, diagnostic, therapeutic and public health implications. Viruses 13, 439.

Song, H.D., Tu, C.C., Zhang, G.W., Wang, S.Y., Zheng, K., Lei, L.C., Chen, Q.X., Gao, Y.W., Zhou, H.Q., Xiang, H., et al. 2005. Crosshost evolution of severe acute respiratory syndrome coronavirus in palm civet and human. Proc. Natl. Acad. Sci. USA 102, 2430 2435.

Stephenson, K.E., Le Gars, M., Sadoff, J., de Groot, A.M., Heerwegh, D., Truyers, C., Atyeo, C., Loos, C., Chandrashekar, A., McMahan, K., et al. 2021. Immunogenicity of the Ad26.COV2.S vaccine for COVID-19. JAMA 325, 1535-1544.

Sternberg, A. and Naujokat, C. 2020. Structural features of coronavirus SARS-CoV-2 spike protein: targets for vaccination. Life Sci. 257, 118056.

Supasa, P., Zhou, D., Dejnirattisai, W., Liu, C., Mentzer, A.J., Ginn, H.M., Zhao, Y., Duyvesteyn, H.M.E., Nutalai, R., Tuekprakhon, A., et al. 2021. Reduced neutralization of SARS-CoV-2 B.1.1.7 variant by convalescent and vaccine sera. Cell 184, 2201-2211.

Tada, T., Zhou, H., Dcosta, B.M., Samanovic, M.I., Mulligan, M.J., and Landau, N.R. 2021. The spike proteins of SARS-CoV-2 B.1.617 and B.1.618 variants identified in India provide partial resistance to vaccine-elicited and therapeutic monoclonal antibodies. bioRxiv. doi: https://doi.org/10.1101/2021.05.14.444076.

Tay, M.Z., Poh, C.M., Rénia, L., MacAry, P.A., and Ng, L.F.P. 2020. The trinity of COVID-19: immunity, inflammation and intervention. Nat. Rev. Immunol. 20, 363-374.

Tian, J.H., Patel, N., Haupt, R., Zhou, H., Weston, S., Hammond, H., Logue, J., Portnoff, A.D., Norton, J., Guebre-Xabier, M., et al. 2021. SARS-CoV-2 S glycoprotein vaccine candidate NVXCoV2373 immunogenicity in baboons and protection in mice. Nat. Commun. 12, 372.

Ura, T., Yamashita, A., Mizuki, N., Okuda, K., and Shimada, M. 2021. New vaccine production platforms used in developing SARSCoV-2 vaccine candidates. Vaccine 39, 197-201.

US FDA, US Food \& Drug Administration. 2020. Coronavirus (COVID-19) update: FDA authorizes monoclonal antibodies for treatment of COVID-19. (accessed 13 May 2021). https://www. fda.gov/news-events/press-announcements/coronavirus-covid19-update-fda-authorizes-monoclonal-antibodies-treatmentcovid-19

Vaduganathan, M., Vardeny, O., Michel, T., McMurray, J.J.V., Pfeffer, M.A., and Solomon, S.D. 2020. Renin-angiotensin-aldosterone system inhibitors in patients with Covid-19. N. Engl. J. Med. 382, 1653-1659.

Verbeke, R., Lentacker, I., De Smedt, S.C., and Dewitte, H. 2021. The dawn of mRNA vaccines: the COVID-19 case. J. Control. Release 333, 511-520.

von Kleist, L., Stahlschmidt, W., Bulut, H., Gromova, K., Puchkov, D., Robertson, M.J., MacGregor, K.A., Tomilin, N., Pechstein, A., Chau, N., et al. 2011. Role of the clathrin terminal domain in regulating coated pit dynamics revealed by small molecule inhibition. Cell 146, 471-484.

Walls, A.C., Park, Y.J., Tortorici, M.A., Wall, A., McGuire, A.T., and Veesler, D. 2020. Structure, function, and antigenicity of the SARS-CoV-2 spike glycoprotein. Cell 181, 281-292.

Wang, P., Casner, R.G., Nair, M.S., Wang, M., Yu, J., Cerutti, G., Liu, L., Kwong, P.D., Huang, Y., Shapiro, L., et al. 2021a. Increased resistance of SARS-CoV-2 variant P.1 to antibody neutralization. Cell Host Microbe 29, 747-751.

Wang, W.B., Liang, Y., Jin, Y.Q., Zhang, J., Su, J.G., and Li, Q.M. 2021b. E484K mutation in SARS-CoV-2 RBD enhances binding affinity with hACE2 but reduces interactions with neutralizing antibodies and nanobodies: binding free energy calculation studies. bioRxiv. doi: https://doi.org/10.1101/2021.02.17.431566.

Wang, P., Nair, M.S., Liu, L., Iketani, S., Luo, Y., Guo, Y., Wang, M., Yu, J., Zhang, B., Kwong, P.D., et al. 2021c. Antibody resistance of SARS-CoV-2 variants B.1.351 and B.1.1.7. Nature 593, 130135.

Wang, Z., Schmidt, F., Weisblum, Y., Muecksch, F., Barnes, C.O., Finkin, S., Schaefer-Babajew, D., Cipolla, M., Gaebler, C., Lieberman, J.A., et al. 2021d. mRNA vaccine-elicited antibodies to SARS-CoV-2 and circulating variants. Nature 592, 616-622.

Wang, Q., Wu, J., Wang, H., Gao, Y., Liu, Q., Mu, A., Ji, W., Yan, L., Zhu, Y., Zhu, C., et al. 2020. Structural basis for RNA replication by the SARS-CoV-2 polymerase. Cell 182, 417-428.

Weinreich, D.M., Sivapalasingam, S., Norton, T., Ali, S., Gao, H., Bhore, R., Musser, B.J., Soo, Y., Rofail, D., Im, J., et al. 2021. REGN-COV2, a neutralizing antibody cocktail, in outpatients with Covid-19. N. Engl. J. Med. 384, 238-251.

Wibmer, C.K., Ayres, F., Hermanus, T., Madzivhandila, M., Kgagudi, P., Oosthuysen, B., Lambson, B.E., de Oliveira, T., Vermeulen, M., van der Berg, K., et al. 2021. SARS-CoV-2 501Y.V2 escapes neutralization by South African COVID-19 donor plasma. Nat. Med. 27, 622-625.

Widera, M., Wilhelm, A., Hoehl, S., Pallas, C., Kohmer, N., Wolf, T., Rabenau, H.F., Corman, V., Drosten, C., Vehreschild, M.J.G.T., et al. 2021. Bamlanivimab does not neutralize two SARS-CoV-2 variants carrying E484K in vitro. medRxiv. doi: https:/doi.org/ 10.1101/2021.02.24.21252372.

Wong, L.H., Edgar, J.R., Martello, A., Ferguson, B.J., and Eden, E.R. 2021. Exploiting connections for viral replication. Front. Cell Dev. Biol. 9, 640456.

Xie, X., Liu, Y., Liu, J., Zhang, X., Zou, J., Fontes-Garfias, C.R., Xia, H., Swanson, K.A., Cutler, M., Cooper, D., et al. 2021. Neutralization of SARS-CoV-2 S 69/70 deletion, E484K and N501Y variants by BNT162b2 vaccine-elicited sera. Nat. Med. 27, 620-621.

Yadav, P.D., Mohandas, S., Shete, A.M., Nyayanit, D.A., Gupta, N., Patil, D.Y., Sapkal, G.N., Potdar, V., Kadam, M., Kumar, A., et al. 2021. SARS CoV-2 variant B.1.617.1 is highly pathogenic in hamsters than B.1 variant. bioRxiv. doi: https://doi.org/10.1101/ 2021.05.05.442760

Yang, X., Yu, Y., Xu, J., Shu, H., Xia, J., Liu, H., Wu, Y., Zhang, L., Yu, Z., Fang, M., et al. 2020. Clinical course and outcomes of critically ill patients with SARS-CoV-2 pneumonia in Wuhan, China: a single-centered, retrospective, observational study. Lancet Respir. Med. 8, 475-481.

Yin, W., Mao, C., Luan, X., Shen, D.D., Shen, Q., Su, H., Wang, X., Zhou, F., Zhao, W., Gao, M., et al. 2020. Structural basis for inhibition of the RNA-dependent RNA polymerase from SARSCoV-2 by remdesivir. Science 368, 1499-1504.

Young, B.E., Ong, S.W.X., Kalimuddin, S., Low, J.G., Tan, S.Y., Loh, J., Ng, O.T., Marimuthu, K., Ang, L.W., Mak, T.M., et al. 2020. Epidemiologic features and clinical course of patients infected with SARS-CoV-2 in Singapore. JAMA 323, 1488-1494.

Zhou, D., Dejnirattisai, W., Supasa, P., Liu, C., Mentzer, A.J., Ginn, H.M., Zhao, Y., Duyvesteyn, H.M.E., Tuekprakhon, A., Nutalai, R., et al. 2021. Evidence of escape of SARS-CoV-2 variant B.1.351 from natural and vaccine-induced sera. Cell 184, 2348-2361.

Zhou, R., To, K.K.W., Wong, Y.C., Liu, L., Zhou, B., Li, X., Huang, H., Mo, Y., Luk, T.Y., Lau, T.T.K., et al. 2020. Acute SARS-CoV-2 infection impairs dendritic cell and $\mathrm{T}$ cell responses. Immunity 53, 864-877. 